\title{
Assessment and management of coagulopathy in neurocritical care
}

\author{
Ahmed M. Salem, MD, MS'; David Roh, MD²; Ryan S. Kitagawa, MD'; \\ Huimahn A. Choi, MD, MS ${ }^{1}$; Tiffany R. Chang, MD' \\ 'Department of Neurosurgery, McGovern Medical School at UTHealth, Houston, TX, USA \\ ${ }^{2}$ Department of Neurology, Columbia University, Vagelos College of Physicians and Surgeons, \\ New York, NY, USA
}

\section{Journal of Neurocritical Care \\ REVIEW ARTICLE \\ Received: May 17, 2019 \\ Revised: June 13, 2019 \\ Accepted: June 15, 2019 \\ Corresponding Author: \\ Tiffany R. Chang, MD \\ Department of Neurosurgery, \\ McGovern Medical School at UTHealth, 6431 Fannin St., MSB 7.154, Houston, TX 77030, USA \\ Tel: +1-713-500-6128 \\ Fax: +1-713-500-0665 \\ E-mail:Tiffany.R.Chang@uth.tmc.edu}

Coagulopathy may be defined as the loss of balance between hemostatic and fibrinolytic processes resulting in excessive bleeding, intravascular thrombosis or abnormalities in coagulation testing. It is frequently encountered across a wide range of conditions seen in the neurocritical care unit and can contribute to poor outcomes. Early recognition and appropriate management are key, with traumatic brain injury, acute ischemic stroke, intracerebral hemorrhage, and subarachnoid hemorrhage presenting unique challenges to the neurointensivist. We will discuss techniques to assess coagulopathies as well as treatment strategies for the brain injured patient.

Keywords: Anticoagulants; Platelet aggregation inhibitors; Blood coagulation disorders; Thrombelastrography; Subarachnoid hemorrhage; Brain injuries, traumatic

\section{INTRODUCTION}

Normal coagulation is a balance between hemostatic and fibrinolytic processes, the loss of which may result in either excessive bleeding or intravascular thrombosis, which defines coagulopathy. Abnormalities in coagulation testing may also be considered evidence of coagulopathy, even in the absence of clinical sequelae of bleeding or thrombosis.

There is limited data on the incidence of coagulopathy in neurocritical care units; however, it is commonly seen in critically ill patients with incidences ranging widely from $14 \%$ to $81 \%[1,2]$. Coagulopathies may be acquired through a variety of conditions including trauma, organ failure and the use of medications, and may confer an increased risk of secondary hematoma expansion, poor functional outcome, and death across the spectrum of neurocritical illnesses [3-6]. An aging patient population and increased use of antithrombotic and anticoagulant agents demand unique considerations $[3,7,8]$. Timely, appropriate assessment and treatment are warranted to mitigate hematoma expansion and to facilitate emergent neurosurgical intervention when indicated. We discuss herein techniques in the assessment and management of coagulopathies for the patient with an intracranial hemorrhage, in line with the most recent guidelines adopted by the American Heart Association (AHA), American Stroke Association (ASA), Neurocritical Care Society (NCS), and Society of Critical Care Medicine (SCCM) $[3,9]$. We include updates from clinical trial findings that 
were not available at the time of these publications.

\section{COAGULATION ASSESSMENT}

\section{Conventional coagulation tests}

Common (or conventional) coagulation tests (CCT) include prothrombin time/international normalized ratio (PT/INR), activated partial thromboplastin time (aPTT), platelet count, D-dimer, and fibrinogen levels. The PT is a laboratory test developed to assess the function of the "extrinsic pathway" whereby calcium and tissue factor (TF) are added to citrated blood and the time to coagulation is measured. To correct for interlaboratory differences in TF preparations, the INR was developed and is only intended for monitoring the effect of warfarin therapy [10]. Abnormalities in PT may reflect coagulopathy seen in liver failure, disseminated intravascular coagulopathy (DIC), trauma as well as in the case of some medications such as factor Xa inhibitors. The aPTT was developed historically to assist in the diagnostic process for patients who exhibit signs consistent with hemophilia [11]. In modern clinical practice, it is commonly used to assess the "intrinsic pathway" of hemostasis and is performed by adding calcium, phospholipid, and an activator such as kaolin to citrated blood, and the time to coagulation is measured. It is most useful for monitoring the effect of unfractionated heparin (UFH); however, it cannot reliably reflect the effect of other anticoagulants [12].

CCTs present limitations in our patient population as they are plasma-based, and hence cannot measure interactions between clotting factors, TF, and platelets, and were not designed to assess hemostatic integrity in the trauma or preoperative patient $[11,13]$; they simply reflect a static evaluation of the coagulation cascade with clot formation as their endpoint rather than assessing the whole coagulation system [13]. They have also been shown to correlate poorly with clinical bleeding and transfusion requirements, lack accuracy in detecting deficiencies in coagulation factors, fail to detect the effects of novel anticoagulation agents or antiplatelet therapy (APT), and do not describe platelet function and fibrinolysis.

\section{Viscoelastic hemostatic assays}

Shortcomings of CCTs have led to increased utilization of viscoelastic hemostatic assays (VHAs), which offer a better depiction of the successive steps that comprise the cell-based theory of hemostasis, i.e., initiation, amplification, propagation, and termination through fibrinolysis. VHAs are performed by placing whole blood in a cup with a suspended pin, which transduces changes in tension during clot formation and breakdown with rotation (Fig. 1) [14].

Thrombelastography (TEG) is a VHA commonly used in North America. TEG measures different phases of the coagulation cascade including time to initiate clot formation (reaction time $[\mathrm{R}]$ ), rate of clot formation (kinetics [K], a angle), maximum clot strength (maximum amplitude [MA]), and clot stability (fibrinolysis; Ly30). When compared with CCT, TEG has been shown to be a better predictor of significant bleeding, the need for massive transfusions as well as mortality at 24 hours and 30 days following trauma [15]. Furthermore, there is a reported mortality benefit to TEG-directed hemostatic resuscitation in trauma patients requir-
A

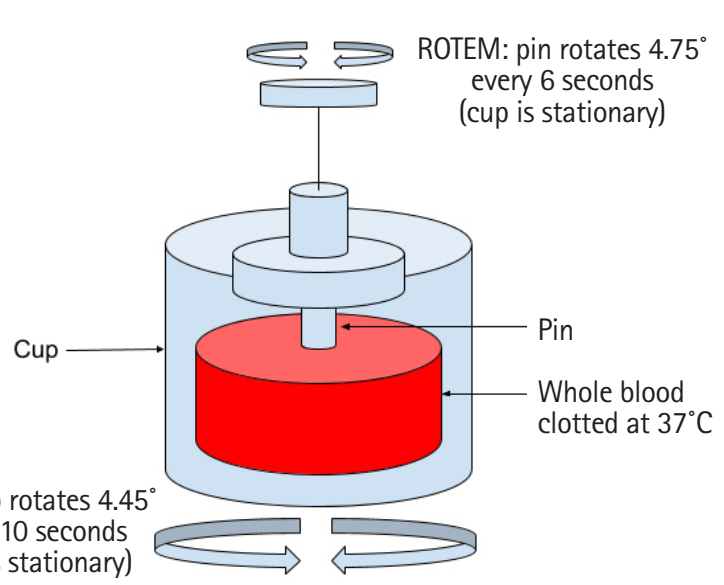

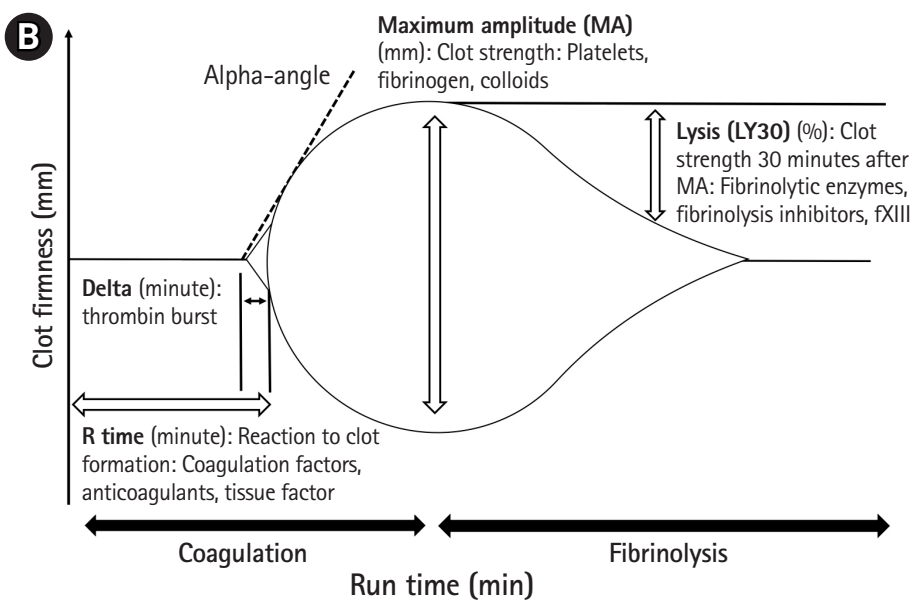

Fig. 1. (A) Schematic of viscoelastic testing with specimen of whole blood in cup. With thrombelastography (TEG) the cup oscillates with pin remaining stationary, while with ROTEM pin oscillates while the cup remains stationary. Measurement of pin synchronization with the cup reflects the stages of clot formation. (B) TEG recording with measurement parameters. 
ing massive transfusions when compared to interventions dictated by CCTs [16-18]. An example of CCT and TEG guided transfusion recommendations implemented at our institution is shown in Table 1.

\section{Platelet function}

While CCT identifies patients at increased risk of bleeding due to thrombocytopenia, it does not indicate; however, qualitative platelet dysfunction due to the use of APT, renal insufficiency or other factors. Bleeding time has grown out of favor for this purpose due its operator-dependence and lack of sensitivity [19]. Light transmission aggregometry in platelet-rich plasma or whole blood is considered the gold standard for assessment of platelet function, but availability may be limited due to poor standardization and time consumption [20]. Commercially available point-of-care platelet function assays overcome some of these obstacles and include the platelet function analyzer (PFA-100, Siemens Medical Solutions, Malvern, PA, USA), VerifyNow (Accumetrics, San Diego, CA, USA) ASA and P2Y12 assays. These tests detect dysfunction secondary to the use of antiplatelets and can provide measures of patient response to these agents as well as adequacy of efforts to reverse them. Standard TEG testing unreliably detects the presence of single APT use; however, it may detect coagulopathy seen in combination APT use [21]. TEG with platelet mapping (TEGPM, Haemoscope Corp., Niles, IL, USA) is a specific VHA that has been shown to correlate with platelet aggregometry and is able to detect platelet dysfunction due to APT and other coagulopa-

Table 1. Memorial Hermann Hospital transfusion recommendations based on abnormal coagulation testing in bleeding patients

\begin{tabular}{ll}
\hline Laboratory value & \multicolumn{1}{c}{ Blood product transfusion } \\
\hline ACT $>128$ & FFP and RBCs \\
$r>1.1$ & FFP and RBCs \\
$k$ time $>2.5$ & Cryoprecipitate/fibrinogen/FFP \\
$\alpha$ angle $<56$ & Cryoprecipitate/fibrinogen/platelets \\
MA $<55$ & Platelets/cryoprecipitate/fibrinogen \\
Ly30 $>3 \%$ & Tranexamic acid \\
PT $>18.0$ sec & FFP \\
aPTT $>35$ sec & FFP \\
INR $>1.5$ & FFP \\
Platelet count $<150 \times 10^{9} / \mathrm{L}$ & Platelets \\
Fibrinogen $<180 \mathrm{~g} / \mathrm{L}$ & Cryoprecipitate/fibrinogen \\
\hline
\end{tabular}

Adapted from Holcomb et al. [15], with permission of Wolters Kluwer Health.

ACT, activated clotting time; FFP, fresh frozen plasma; RBC, red blood cells; MA, maximum amplitude; Ly30, percentage of lysis 30 minutes after MA; PT, prothrombin time; aPT, activated partial thromboplastin time; INR, international normalized ratio. thies. In neurocritically ill patients, such as those with subarachnoid hemorrhage (SAH), intracerebral hemorrhage (ICH), or traumatic brain injury (TBI), platelet dysfunction may be seen even in the absence of APT use or failure of other organ systems and may confer worse outcomes [22-24].

\section{COAGULOPATHY IN ACUTE BRAIN INJURY}

Historically, reports dating back to the 1970s described baseline hypercoagulability based on TEG in patients with acute ischemic stroke (AIS) and SAH $[25,26]$. The more recent use of TEG in the neurocritical care unit has allowed investigators to better elucidate coagulopathies seen in different types of acute brain injury. In general, patients with acute brain injuries present with hypercoagulable states compared with normal controls. The impact of this response, variations in this response between patients with the same type of injury, and potential therapeutic implications largely remain unclear.

\section{Acute ischemic stroke}

Patients with AIS have been reported to present with a hypercoagulable state when compared with normal controls. In a study of patients with AIS presenting within the window of administering tissue plasminogen activator (tPA) (i.e., within 3 hours), TEG demonstrated a hypercoagulable state based on shorter $\mathrm{R}$ and $\mathrm{K}$ times with greater $a$ angle. After treatment with $\mathrm{tPA}$, significant changes in MA, G, and Ly30 were demonstrated within 10 minutes [27]. However, the same group was unable to predict a clinical response to tPA treatment using TEG values [28].

Admission TEG values have been associated with outcomes after AIS. In another study utilizing TEG in patients with AIS, MA was found to be an independent predictor of poor outcome (modified Rankin Score $\geq 2$ ) at 1 year. Recurrence rate of ischemic events were found to be higher in the 3rd MA tertile group, despite higher rates of treatment with dual APT. Higher tertile of MA was also associated with stroke severity (higher National Institutes of Health Stroke Scale scores on admission and longer hospital stay) [29]. Although MA appears to be a marker of stroke severity and may portend worse outcome, it is unclear if this may be a potential target for intervention.

\section{Intracerebral hemorrhage}

Studies utilizing TEG in patients with ICH have illustrated its potential in predicting the clinical course. In a study by Kawano-Castillo et al. [30], patients with ICH demonstrated faster and stronger clot formation at baseline (shorter $\mathrm{R}$ and delta) and stronger clot strength (higher MA and G) at 36 hours compared with normal 
controls. Patients with hematoma expansion had significantly longer baseline $\mathrm{K}$ and delta compared with nonexpanders, indicating that the former group had slower clot formation [30]. Other reports have also demonstrated greater baseline hypercoagulability in patients with $\mathrm{ICH}[31,32]$.

Although patients with ICH often present with a hypercoagulable state compared with controls, hypocoagulability may have a powerful impact on outcome from ICH. Hypocoagulability by TEG has been associated with worse functional outcome, higher rates of cerebral herniation, and mortality from $\mathrm{ICH}$ and isolated TBI [33]. Detection of hypocoagulability could represent an application of TEG in terms of therapeutic implications in ICH.

\section{Subarachnoid hemorrhage}

Like AIS and ICH, baseline coagulation disturbances are common in the spontaneous SAH population. In animal models of SAH, hypercoagulability is demonstrated as early as $\mathbf{3 0}$ minutes following the injury [34]. In patients with SAH, early hypercoagulability and platelet dysfunction has been identified by TEG and shown to correlate with poor outcomes, including an increased incidence of delayed cerebral ischemia and worse modified Rankin Scores at 3 months [22]. Similar to AIS, there is an association noted between elevated MA values and poor outcomes, independent of other inflammatory biomarkers, age, and Hunt-Hess grade [35].

\section{Traumatic brain injury}

Trauma population studies have elucidated some of the complex coagulation disturbances which occur in the setting of traumatic injury. Furthermore, more widespread use of TEG has enhanced the ability to detect coagulation differences. In general, hypercoagulability by TEG is the most commonly observed pattern in trauma and may be observed in up to $65 \%$ of patients [36]. However, a subset of patients may present with an acute traumatic coagulopathy. Hypocoagulability on admission is associated with a several-fold increase in morbidity and mortality [37]. Findings seen most often with severe injuries include elevated PT/partial thromboplastin time, low platelet counts, and fibrinogen levels on CCT. TEG has demonstrated hypocoagulability in severe trauma through changes in the values of R, $a$ angle, and MA. Hyperfibrinolysis, while only seen in $2 \%$ to $6 \%$ of patients, may have a powerful impact on outcome from major trauma. Ly30 values greater than $3 \%$ have been associated a two-fold increase in mortality in trauma patients [15]. Patients with massive tissue injury have also demonstrated evidence of hyperfibrinolysis, such as elevated D-dimer and fibrin degradation products on CCT [38]. As previously discussed, TEG based protocols may now be used to guide transfusion therapy in the setting of traumatic injury.
Coagulopathy following TBI is associated with the severity of injury. In one report, it was present in up to one-third of patients with isolated TBI and up to $60 \%$ of patients with severe TBI, although there have been reports of lower rates [39]. The brain is rich in TF and it is postulated that its release activates the extrinsic pathway, which in turn leads to a consumptive coagulopathy and hyperfibrinolysis. Evidence of coagulopathy on TEG (e.g., increased R or decreased MA) following isolated TBI has been shown to be associated with considerably higher rates of mortality when compared to TBI patients without evidence of coagulopathy (66\% vs. $16.6 \%$ ) [40]. Hyperfibrinolysis also continues to play an important role in predicting poor outcome in patients with TBI, with $\mathrm{D}$-dimer at admission shown to be an independent risk factor for poor outcome [41].

\section{COAGULOPATHY IN SYSTEMIC DISEASE}

\section{Acute liver failure}

Acute liver failure is associated with a deficiency of both procoagulant and anticoagulant proteins. While CCT may show an elevated $\mathrm{PT} / \mathrm{INR}$ in this patient population, TEG has demonstrated that the vast majority of these patients have a normal ability to form clots and may even be hypercoagulable [42].

\section{Thrombocytopenia}

Thrombocytopenia may be seen in a variety of conditions encountered in the neurocritical care unit, including sepsis (which is the most common cause of thrombocytopenia in critically ill patients), hypersplenism, DIC, blood loss, mechanical fragmentation, medications, bone marrow suppression, and immune-mediated disorders [43]. In a case series by Chan et al. [44] of patients with thrombocytopenia undergoing neurosurgical procedures, a platelet count $<100,000 / \mu \mathrm{L}$ was associated with a significant increase in the rate of postoperative hematoma formation when compared with patients with a platelet count $>100,000 / \mu \mathrm{L}$. Current guidelines recommend a transfusion threshold of $<100,000$ / $\mu \mathrm{L}$ for patients with intracranial bleeding or those undergoing a neurosurgical procedure.

\section{Disseminated intravascular coagulopathy}

DIC is associated with multiple disease entities encountered in critically ill patients, most commonly due to sepsis, although trau$\mathrm{ma}$ and malignancy are also common causes encountered in the neurocritical care unit [45]. It is characterized by widespread microvascular thrombosis due to TF expression, leading to massive fibrin deposition, consumption of platelets and coagulation factors, hyperfibrinolysis, hemorrhage, and organ failure [46]. The man- 
agement of DIC is that of the underlying condition and CCT-guided transfusion if a patient is actively bleeding or at high risk of bleeding.

\section{Uremia}

Uremia is associated with an increased risk of hemorrhage secondary to platelet dysfunction. A rising prevalence of chronic kidney disease and the use of renal replacement therapy has led to this being encountered with increasing frequency in the neurocritical care unit as a cause of, or contributing to, intracranial bleeding $[47,48]$. Desmopressin (DDAVP) is the agent most commonly used in the treatment of uremic bleeding and has been shown to reduce bleeding time and normalize hemostasis in patients with uremic platelets undergoing surgery $[49,50]$. Its actions are mediated by an increase in endothelial release of von Willebrand factor and platelet membrane glycoprotein expression, which in turn promotes platelet adhesion to the endothelium $[51,52]$. It has been shown to restore platelet function within 30 minutes of administration, though its effects are short-lived at around 3 hours [53]. DDAVP is dosed at $0.4 \mu \mathrm{g} / \mathrm{kg}$ administered intravenously for this indication and is well tolerated with few reported side effects $[3,12,54]$.

\section{REVERSAL OF ANTITHROMBOTIC THERAPY}

There has been a significant, continued increase in the use of antithrombotic agents among patients admitted to the neurocritical care unit, due to an aging population and increased diagnosis of ischemic events that warrant such therapies. The introduction of novel agents poses a diagnostic and therapeutic dilemma for the neurointensivist when managing the patient with intracranial hemorrhage. Antithrombotic agents may be roughly divided into APT and anticoagulant therapy.

\section{Antiplatelet therapy}

The main classes of antiplatelet drugs commonly used in practice include cyclooxygenase-1 (COX-1) inhibitors (e.g., acetylsalicylic acid; ASA or aspirin), phosphodiesterase inhibitors (e.g., dipyridamole and cilostazol), P2Y12 receptor inhibitors (e.g., clopidogrel, prasugrel, and ticagrelor) and glycoprotein Ilb/IIIa inhibitors (e.g., abciximab, eptifibatide, and tirofiban). Aspirin use confers an absolute risk increase of $0.1 \%$ per year of ICH compared to control [55]. Clopidogrel carried a similar rate of ICH incidence when compared to aspirin in the Clopidogrel versus Aspirin in Patients at Risk of Ischemic Events (CAPRIE) trial [56]. Prasugrel, when compared to clopidogrel in the Trial to Assess Improvement in Therapeutic Outcomes by Optimizing Platelet Inhibition With Prasugrel-Thrombolysis in Myocardial Infarction 38 (TRI-
TON-TIMI 38) trial, demonstrated a higher risk of life-threatening bleeding overall although the rate of $\mathrm{ICH}$ was similar between the two groups [57]. Ticagrelor was associated with an increased rate of intracranial hemorrhage when compared to clopidogrel in the Platelet Inhibition and Patient Outcomes (PLATO) trial, although this difference was nonsignificant [58]. Single APT use is associated with a low risk of major bleeding, although this risk increases significantly when combination APT are implemented, similar to the risk of anticoagulants $[12,59]$. In a study of a large cohort of patients from the Get With The Guidelines-Stroke (GWTG-Stroke) database with $\mathrm{ICH}$, the use of combination APT, but not single APT, was associated with a higher risk for in-hospital mortality when compared with patients not taking APT [60].

Reversal of APT in the bleeding patient may be achieved through the administration of platelet transfusion. Routine platelet transfusion for ICH based on reported use of APT alone was associated with an increased rate of poor functional outcome in the Platelet Transfusion in Spontaneous Intracerebral Hemorrhage (PATCH) trial [61]. It is important to note that this trial did not utilize qualitative platelet function testing and excluded surgical patients, so platelet transfusion may be appropriate for patients who require neurosurgical intervention. In a study by Choi et al. [62] of 107 patients presenting with traumatic intracranial hemorrhage and reported APT use, a significant percentage of patients had subtherapeutic ASA/P2Y12 assays that would be unlikely to benefit from platelet transfusion. Among patients that did receive platelet transfusions, the amount transfused did not adequately reverse its effect in almost half of this patient cohort [62]. There may, therefore, be a role for targeted platelet transfusions based on quantitative assessment of platelet function before and after transfusion. This was illustrated in a retrospective study by Naidech et al. [63] on a series of patients with $\mathrm{ICH}$ and abnormal platelet function activity. Early ( $<12$ hours from symptom onset) platelet transfusion improved platelet activity assay results and was associated with smaller final hemorrhage size and more independence at 3 months (modified Rankin Score <4) [63]. Similarly, in a TBI population, TEG-directed platelet transfusion was associated with a decreased mortality compared to a historical cohort in a retrospective study by Furay et al. [64].

DDAVP use has also been demonstrated to improve platelet function in patients on COX-1 and ADP receptor inhibitors in several tests of platelet function compared to those who had not received reversal agents [3,50,51,65-68]. Clinically, it has been shown to reduce blood loss and improve hemostasis in patients with aspirin exposure undergoing cardiac surgery $[49,69,70]$. In two small studies of patients with intracranial hemorrhage and either reduced platelet activity on PFA-100 and/or known aspirin 
use, DDAVP administration was associated with restoration of platelet function on repeat testing $[53,71]$. Given its low cost and relatively good safety profile, its administration should be considered in patients with intracranial hemorrhage who were exposed to antiplatelet agents [3].

\section{Anticoagulation therapy}

The main classes of anticoagulant drugs include vitamin K-dependent coagulation factor antagonists (VKA, e.g., warfarin), factor Xa inhibitors (e.g., fondaparinux, rivaroxaban, apixaban), direct thrombin inhibitors (DTI, e.g., argatroban, bivalirudin, dabigatran), and heparinoids (i.e., unfractionated, or UFH, and low-molecular-weight heparin $[\mathrm{LMWH}])$. In the neurocritical care unit, common indications for these medications include stroke prevention in atrial fibrillation and treatment of venous thromboembolism. Reversal strategies for anticoagulation-associated intracranial hemorrhage are summarized in Table 2.

\section{Vitamin Kantagonists}

VKA inhibit vitamin K-dependent factors in the coagulation cascade: factors II, VII, IX, and X. VKA activity can be assessed by PT/INR. The risk of bleeding while taking a VKA increases with the duration of therapy and higher INR levels. For each increment in INR elevation above the therapeutic range, the risk of bleeding on a VKA doubles [72].

Vitamin $\mathrm{K}$ replacement is essential to replenish the vitamin K-dependent factors and reverse VKA activity. It should be given promptly and IV administration mitigates variability in oral vita$\min \mathrm{K}$ absorption. Although the risk profile is low, it may take 24 hours or more to become effective [3].

Fresh frozen plasma (FFP) has been conventionally used to reverse VKA in conjunction with vitamin $\mathrm{K}$. Although it is relatively inexpensive and widely available, its use is complicated by delays in administration, potential transfusion related reactions, and large volumes which may be required for full INR reversal. This had led to the more widespread use of prothrombin complex concentrate (PCC). PCC is derived from plasma and contains factors II, VII, $\mathrm{IX}$, and $\mathrm{X}$ in variable proportions in different preparations. It is rapidly administered in a small volume. PCC has been demonstrated to reverse INR to $<1.4$ and maintain INR reversal for $>48$ hours in the majority of patients on VKA therapy [73]. In the INR Normalization in Coumadin Associated Intracerebral Haemorrhage (INCH) trial, a randomized trial comparing FFP and PCC for VKA reversal in intracranial hemorrhage, $\mathrm{PCC}$ provided more rapid INR reversal with an effective reduction in hematoma expansion [74]. The trial was stopped early due to safety concerns with FFP therapy. Both the AHA/ASA as well as the NCS/SCCM guidelines currently recommend consideration of PCC over FFP for VKA reversal in $\mathrm{ICH}[3,9]$.

\section{Factor Xa inhibitors}

$\mathrm{Xa}$ inhibitors prevent the conversion of prothrombin to thrombin. Detection of novel agents using calibrated chromogenic assays are expensive and not readily available, and the utility of existing anti-Xa assays have not been validated to identify the presence of the oral factor Xa inhibitors. There is data to support the use of TEG to detect coagulopathies induced by these agents, which may inform reversal strategies in these patients [75].

Table 2. Summary of common anticoagulation agents and Neurocritical Care Society guidelines for the reversal in intracranial hemorrhage

\begin{tabular}{|c|c|c|c|}
\hline Agent & Mechanism & Half-life & Reversal \\
\hline \multirow[t]{3}{*}{ Warfarin } & $\begin{array}{l}\text { Reduction in vitamin K-dependent } \\
\text { clotting factors (II, VII, IX, X) }\end{array}$ & $20-60 \mathrm{hr}$ & Vitamin K 10 mg IV \\
\hline & & & PCC 25-50 U/kg \\
\hline & & & FFP $10-15 \mathrm{~mL} / \mathrm{kg}$ if PCC not available \\
\hline \multirow[t]{3}{*}{ Dabigatran } & Direct thrombin inhibitor & $13 \mathrm{hr}$ & Idarucizumab 5 mg IV \\
\hline & & $22-35 \mathrm{hr}$ if $\mathrm{CrCl}$ & PCC if idarucizumab not available \\
\hline & & $<30$ & Hemodialysis \\
\hline \multirow[t]{2}{*}{ Rivaroxaban, apixaban, edoxaban } & Xa inhibitor & Rivaroxaban 7-9 hr & PCC $50 \mathrm{U} / \mathrm{kg}$ \\
\hline & & Apixaban 9-14 hr & Andexanet alpha \\
\hline Heparin & $\begin{array}{l}\text { Indirectly inhibits Xa and Ila via } \\
\text { antithrombin }\end{array}$ & $60-90 \mathrm{~min}$ & $\begin{array}{l}\text { Protamine } 1 \mathrm{mg} \text { per } 100 \mathrm{U} \text { heparin given within } \\
\text { past } 2-3 \mathrm{hr}\end{array}$ \\
\hline \multirow[t]{3}{*}{ Enoxaparin } & Same as heparin but mainly $\mathrm{Xa}$ & $4 \mathrm{hr}$ & Protamine reverses approximately $60 \%$ of effect \\
\hline & & & $<8 \mathrm{hr}: 1 \mathrm{mg}$ per $1 \mathrm{mg}$ enoxaparin \\
\hline & & & 8-12 hr: 0.5 mg per 1 mg enoxaparin \\
\hline
\end{tabular}

Adapted from Frontera et al. [3], with permission of Springer Nature.

$\mathrm{IV}$, intravenous; $\mathrm{PCC}$, prothrombin complex concentrate; FFP, fresh frozen plasma; $\mathrm{CrCl}$, creatinine clearance. 
PCC is commonly used for Xa inhibitor reversal. PCC has been demonstrated to effectively reverse rivaroxaban in healthy volunteers [76]. In the setting of intracranial bleeding, it is recommended to administer 50 units $/ \mathrm{kg}$ if the medication was ingested within 3 to 5 half lives or if the time of last exposure is unknown. In patients with a known ingestion within 2 hours, activated charcoal may also be utilized if this is deemed safe from an airway protection standpoint. Hemodialysis is not effective in removing Xa inhibitors [3].

Andexanet alpha is a recombinant inactive form of factor Xa. It binds to Xa inhibitors with high affinity and sequesters the medication, resulting in reduced anti Xa activity. In the Andexanet Alfa, a Novel Antidote to the Anticoagulation Effects of FXA Inhibitors-4 (ANNEXA-4) study of 352 patients with major bleeding, andexanet alpha reduced anti Xa levels by $92 \%$ in rivaroxaban/apixaban treated patients and 75\% in enoxaparin [77]. Andexanet alpha is approved by the U.S. Food and Drug Adminstration for the reversal of rivaroxaban and apixaban, but widespread use is limited due to the cost of the medication.

\section{Direct thrombin inhibitors}

DTI directly inhibit the activity of factor IIa, which is the key factor in converting fibrinogen to fibrin. DTI have an additional unique indication in the treatment of heparin induced thrombocytopenia. Intravenous formulations are short acting and generally do not require reversal agents. However, the reversal of oral dabigatran was challenging before idarucizumab became available. Idarucizumab is a monoclonal antibody which binds to dabigatran with considerably higher affinity than factor IIa. In the Reversal Effects of Idarucizumab on Active Dabigatran (RE-VERSE AD) study of 503 patients with life-threatening bleeding (Group A) or need for emergent surgical procedure (Group B), idarucizumab reversed thrombin time to normal in $100 \%$ of patients and this effect remained relatively stable 24 hours after treatment. Normal intraoperative hemostasis was achieved in $92 \%$ of the patients in Group B [78]. The rate of thrombotic events in this study was similar to those reported after major surgical procedures or hospitalization for uncontrolled bleeding, and may be attributable to the low rate of reinitiation of anticoagulation $[79,80]$. Idarucizumab is administered in 2 doses of $2.5 \mathrm{~g}$ given within 15 minutes. Activated charcoal is an additional option for dabigatran, similar to Xa inhibitors, and is recommended for consideration in the AHA/ASA as well as the NCS/SCCM guidelines [3,9].

If idarucizumab is not available, hemodialysis and PCC are alternative options. Dabigatran is renally excreted and is effectively removed by hemodialysis. However, there is a theoretical risk of worsening cerebral edema in patients with mass lesions. The rec- ommended dosing for PCC is 50 units $/ \mathrm{kg}$, the same as for Xa inhibitors. Administration of PCC beyond 3 to 5 half lives of dabigatran exposure may be considered in patients with renal insufficiency $[3,9]$.

\section{Heparin and low-molecular-weight-heparin}

UFH activates antithrombin III activity, which inhibits factors IIa, and Xa. Heparin activity can be assessed utilizing aPTT or pointof-care activated clotting time. Heparin activity may also be assessed with TEG; shortening of R time with heparinase implicates the presence of heparin in the sample as the cause of coagulopathy. Its effects may be reversed with protamine, which is a naturally occurring protein that binds to heparin and its dosing is outlined in Table 2.

LMWH has a similar mechanism of action but is longer acting and thought to have more predictable pharmacology in the setting of normal renal function. Assessment of LMWH activity requires the use of an anti-FXa assay. Protamine may be used to reverse LMWH activity, but this reversal is incomplete and estimated to be around 60\% [3]. A novel approach to LMWH is andexanet alpha. Although this is a potential therapeutic intervention with a possibility of more complete LMWH reversal than with protamine, it is currently not approved for this indication and is still undergoing further study [77].

\section{CONCLUSION}

Coagulopathy is commonly encountered in the neurocritical care unit and poses a challenge to the clinician when managing the patient with intracranial hemorrhage. Utilization of viscoelastic testing has shown great promise in this arena, allowing one to risk stratify patients and guide transfusion requirements. As the widespread use of antithrombotic therapy continues to increase, further development of specific testing for individual medications and targeted reversal agents would improve the management of hemorrhagic complications.

\section{ARTICLE INFORMATION}

\section{Conflict of interest}

No potential conflict of interest relevant to this article.

\section{ORCID}

Ahmed M. Salem, https://orcid.org/0000-0001-9589-7305

David Roh, https://orcid.org/0000-0003-1927-7686

Huimahn A. Choi, https://orcid.org/0000-0001-7218-832X 


\section{Author contributions}

Conceptualization: AMS and TRC. Data curation \& Formal analysis: AMS, RSK, and TRC. Visualization \& Writing-original draft: AMS and DR. Writing-review editing: AMS, DR, HAC, and TRC.

\section{REFERENCES}

1. Levi M, Opal SM. Coagulation abnormalities in critically ill patients. Crit Care 2006;10:222.

2. Strauss R, Wehler M, Kreutzer D, Mehler K, Mueller A, Koebnick $\mathrm{C}$, et al. Incidence and implications of coagulopathy in medical intensive care patients. Crit Care 2001;5(Suppl 1):P105.

3. Frontera JA, Lewin JJ 3rd, Rabinstein AA, Aisiku IP, Alexandrov AW, Cook AM, et al. Guideline for reversal of antithrombotics in intracranial hemorrhage: a statement for healthcare professionals from the Neurocritical Care Society and Society of Critical Care Medicine. Neurocrit Care 2016;24:6-46.

4. Abdelmalik PA, Boorman DW, Tracy J, Jallo J, Rincon F. Acute traumatic coagulopathy accompanying isolated traumatic brain injury is associated with worse long-term functional and cognitive outcomes. Neurocrit Care 2016;24:361-70.

5. Franke CL, de Jonge J, van Swieten JC, Op de Coul AA, van Gijn J. Intracerebral hematomas during anticoagulant treatment. Stroke 1990;21:726-30.

6. Flibotte JJ, Hagan N, O’Donnell J, Greenberg SM, Rosand J. Warfarin, hematoma expansion, and outcome of intracerebral hemorrhage. Neurology 2004;63:1059-64.

7. Flaherty ML, Kissela B, Woo D, Kleindorfer D, Alwell K, Sekar $\mathrm{P}$, et al. The increasing incidence of anticoagulant-associated intracerebral hemorrhage. Neurology 2007;68:116-21.

8. Veltkamp R, Rizos T, Horstmann S. Intracerebral bleeding in patients on antithrombotic agents. Semin Thromb Hemost 2013;39:963-71.

9. Hemphill JC 3rd, Greenberg SM, Anderson CS, Becker K, Bendok BR, Cushman M, et al. Guidelines for the management of spontaneous intracerebral hemorrhage: a guideline for healthcare professionals from the American Heart Association/American Stroke Association. Stroke 2015;46:2032-60.

10. Hirsh J, Poller L. The international normalized ratio. A guide to understanding and correcting its problems. Arch Intern Med 1994;154:282-8.

11. Kitchens CS. To bleed or not to bleed? Is that the question for the PTT? J Thromb Haemost 2005;3:2607-11.

12. Vanderwerf JD, Kumar MA. Management of neurologic complications of coagulopathies. Handb Clin Neurol 2017;141:743-64.

13. Walsh M, Fritz S, Hake D, Son M, Greve S, Jbara M, et al. Tar- geted thromboelastographic (TEG) blood component and pharmacologic hemostatic therapy in traumatic and acquired coagulopathy. Curr Drug Targets 2016;17:954-70.

14. Sankarankutty A, Nascimento B, Teodoro da Luz L, Rizoli S. TEG $®$ and ROTEM $®$ in trauma: similar test but different results? World J Emerg Surg 2012;7 Suppl 1:S3.

15. Holcomb JB, Minei KM, Scerbo ML, Radwan ZA, Wade CE, Kozar RA, et al. Admission rapid thrombelastography can replace conventional coagulation tests in the emergency department: experience with 1974 consecutive trauma patients. Ann Surg 2012;256:476-86.

16. Gonzalez E, Moore EE, Moore HB, Chapman MP, Chin TL, Ghasabyan A, et al. Goal-directed hemostatic resuscitation of trauma-induced coagulopathy: a pragmatic randomized clinical trial comparing a viscoelastic assay to conventional coagulation assays. Ann Surg 2016;263:1051-9.

17. Tapia NM, Chang A, Norman M, Welsh F, Scott B, Wall MJ Jr, et al. TEG-guided resuscitation is superior to standardized MTP resuscitation in massively transfused penetrating trauma patients. J Trauma Acute Care Surg 2013;74:378-85.

18. Johansson PI, Stensballe J. Effect of haemostatic control resuscitation on mortality in massively bleeding patients: a before and after study. Vox Sang 2009;96:111-8.

19. Collyer TC, Gray DJ, Sandhu R, Berridge J, Lyons G. Assessment of platelet inhibition secondary to clopidogrel and aspirin therapy in preoperative acute surgical patients measured by Thrombelastography Platelet Mapping. BrJ Anaesth 2009;102:492-8.

20. Sibbing D, Braun S, Jawansky S, Vogt W, Mehilli J, Schömig A, et al. Assessment of ADP-induced platelet aggregation with light transmission aggregometry and multiple electrode platelet aggregometry before and after clopidogrel treatment. Thromb Haemost 2008;99:121-6.

21. McDonald MM, Almaghrabi TS, Saenz DM, Cai C, Rahbar $\mathrm{MH}$, Choi HA, et al. Dual antiplatelet therapy is associated with coagulopathy detectable by thrombelastography in acute stroke. J Intensive Care Med 2017 Jan 1 [Epub]. https://doi. org/10.1177/0885066617729644.

22. Frontera JA, Provencio JJ, Sehba FA, McIntyre TM, Nowacki AS, Gordon E, et al. The role of platelet activation and inflammation in early brain injury following subarachnoid hemorrhage. Neurocrit Care 2017;26:48-57.

23. Naidech AM, Jovanovic B, Liebling S, Garg RK, Bassin SL, Bendok BR, et al. Reduced platelet activity is associated with early clot growth and worse 3-month outcome after intracerebral hemorrhage. Stroke 2009;40:2398-401.

24. Lindblad C, Thelin EP, Nekludov M, Frostell A, Nelson DW, Svensson M, et al. Assessment of platelet function in traumatic 
brain injury: a retrospective observational study in the neuro-critical care setting. Front Neurol 2018;9:15.

25. Ettinger MG. Coagulation abnormalities in subarachnoid hemorrhage. Stroke 1970;1:139-42.

26. Ettinger MG. Thromboelastographic studies in cerebral infarction. Stroke 1974;5:350-4.

27. Elliott A, Wetzel J, Roper T, Pivalizza E, McCarthy J, Wallace C, et al. Thromboelastography in patients with acute ischemic stroke. Int J Stroke 2015; 10:194-201.

28. McDonald MM, Wetzel J, Fraser S, Elliott A, Bowry R, Kawano-Castillo JF, et al. Thrombelastography does not predict clinical response to rtPA for acute ischemic stroke. J Thromb Thrombolysis 2016;41:505-10.

29. Yao X, Dong Q, Song Y, Wang Y, Deng Y, Li Y. Thrombelastography maximal clot strength could predict one-year functional outcome in patients with ischemic stroke. Cerebrovasc Dis 2014;38:182-90.

30. Kawano-Castillo J, Ward E, Elliott A, Wetzel J, Hassler A, McDonald $\mathrm{M}$, et al. Thrombelastography detects possible coagulation disturbance in patients with intracerebral hemorrhage with hematoma enlargement. Stroke 2014;45:683-8.

31. Lauridsen SV, Hvas AM, Sandgaard E, Gyldenholm T, Rahbek $\mathrm{C}$, Hjort $\mathrm{N}$, et al. Coagulation profile after spontaneous intracerebral hemorrhage: a cohort study. J Stroke Cerebrovasc Dis 2018;27:2951-61.

32. Kang DW, Han MK, Kim HJ, Yun SC, Jeon SB, Bae HJ, et al. New ischemic lesions coexisting with acute intracerebral hemorrhage. Neurology 2012;79:848-55.

33. Windeløv NA, Welling KL, Ostrowski SR, Johansson PI. The prognostic value of thrombelastography in identifying neurosurgical patients with worse prognosis. Blood Coagul Fibrinolysis 2011;22:416-9.

34. Larsen CC, Hansen-Schwartz J, Nielsen JD, Astrup J. Blood coagulation and fibrinolysis after experimental subarachnoid hemorrhage. Acta Neurochir (Wien) 2010;152:1577-81.

35. Ramchand P, Nyirjesy S, Frangos S, Doerfler S, Nawalinski K, Quattrone F, et al. Thromboelastography parameter predicts outcome after subarachnoid hemorrhage: an exploratory analysis. World Neurosurg 2016;96:215-21.

36. Schreiber MA, Differding J, Thorborg P, Mayberry JC, Mullins RJ. Hypercoagulability is most prevalent early after injury and in female patients. J Trauma 2005;58:475-80.

37. Hess JR, Brohi K, Dutton RP, Hauser CJ, Holcomb JB, Kluger Y, et al. The coagulopathy of trauma: a review of mechanisms. J Trauma 2008;65:748-54.

38. Johansson PI, Stissing T, Bochsen L, Ostrowski SR. Thrombelastography and tromboelastometry in assessing coagulopathy in trauma. Scand J Trauma Resusc Emerg Med 2009;17:45.

39. Harhangi BS, Kompanje EJ, Leebeek FW, Maas AI. Coagulation disorders after traumatic brain injury. Acta Neurochir (Wien) 2008;150:165-75.

40. de Oliveira Manoel AL, Neto AC, Veigas PV, Rizoli S. Traumatic brain injury associated coagulopathy. Neurocrit Care 2015;22:3444.

41. Nakae R, Takayama Y, Kuwamoto K, Naoe Y, Sato H, Yokota H. Time course of coagulation and fibrinolytic parameters in patients with traumatic brain injury. J Neurotrauma 2016;33:68895.

42. Stravitz RT, Lisman T, Luketic VA, Sterling RK, Puri P, Fuchs M, et al. Minimal effects of acute liver injury/acute liver failure on hemostasis as assessed by thromboelastography. J Hepatol 2012;56:129-36.

43. Greinacher A, Selleng K. Thrombocytopenia in the intensive care unit patient. Hematology Am Soc Hematol Educ Program 2010;2010:135-43.

44. Chan KH, Mann KS, Chan TK. The significance of thrombocytopenia in the development of postoperative intracranial hematoma.J Neurosurg 1989;71:38-41.

45. Hunt BJ. Bleeding and coagulopathies in critical care. Surv Anesthesiol 2014;58:274-5.

46. Levi M, Toh CH, Thachil J, Watson HG. Guidelines for the diagnosis and management of disseminated intravascular coagulation. British Committee for Standards in Haematology. Br J Haematol 2009; 145:24-33.

47. Roderick P, Davies R, Jones C, Feest T, Smith S, Farrington K. Simulation model of renal replacement therapy: predicting future demand in England. Nephrol Dial Transplant 2004; 19:692-701.

48. Pavord S, Myers B. Bleeding and thrombotic complications of kidney disease. Blood Rev 2011;25:271-8.

49. Mannucci PM, Vicente V, Vianello L, Cattaneo M, Alberca I, Coccato MP, et al. Controlled trial of desmopressin in liver cirrhosis and other conditions associated with a prolonged bleeding time. Blood 1986;67:1148-53.

50. Kim JH, Baek CH, Min JY, Kim JS, Kim SB, Kim H. Desmopressin improves platelet function in uremic patients taking antiplatelet agents who require emergent invasive procedures. Ann Hematol 2015;94:1457-61.

51. Zeigler ZR, Megaludis A, Fraley DS. Desmopressin (d-DAVP) effects on platelet rheology and von Willebrand factor activities in uremia. Am J Hematol 1992;39:90-5.

52. Gordz S, Mrowietz C, Pindur G, Park JW, Jung F. Effect of desmopressin (DDAVP) on platelet membrane glycoprotein expression in patients with von Willebrand's disease. Clin Hemorheol Microcirc 2005;32:83-7. 
53. Kapapa T, Röhrer S, Struve S, Petscher M, König R, Wirtz CR, et al. Desmopressin acetate in intracranial haemorrhage. Neurol Res Int 2014;2014:298767.

54. Van Herzeele C, De Bruyne P, Evans J, Eggert P, Lottmann H, Norgaard JP, et al. Safety profile of desmopressin tablet for enuresis in a prospective study. Adv Ther 2014;31:1306-16.

55. He J, Whelton PK, Vu B, Klag MJ. Aspirin and risk of hemorrhagic stroke: a meta-analysis of randomized controlled trials. JAMA 1998;280:1930-5.

56. Creager MA. Results of the CAPRIE trial: efficacy and safety of clopidogrel. Clopidogrel versus aspirin in patients at risk of ischaemic events. Vasc Med 1998;3:257-60.

57. Wiviott SD, Braunwald E, McCabe CH, Montalescot G, Ruzyllo W, Gottlieb S, et al. Prasugrel versus clopidogrel in patients with acute coronary syndromes. N Engl J Med 2007;357:200115.

58. Wallentin L, Becker RC, Budaj A, Cannon CP, Emanuelsson H, Held C, et al. Ticagrelor versus clopidogrel in patients with acute coronary syndromes. N Engl J Med 2009;361:1045-57.

59. ACTIVE Writing Group of the ACTIVE Investigators, Connolly S, Pogue J, Hart R, Pfeffer M, Hohnloser S, et al. Clopidogrel plus aspirin versus oral anticoagulation for atrial fibrillation in the Atrial fibrillation Clopidogrel Trial with Irbesartan for prevention of Vascular Events (ACTIVE W): a randomised controlled trial. Lancet 2006;367:1903-12.

60. Khan NI, Siddiqui FM, Goldstein JN, Cox M, Xian Y, Matsouaka $\mathrm{RA}$, et al. Association between previous use of antiplatelet therapy and intracerebral hemorrhage outcomes. Stroke 2017;48:1810-7.

61. Baharoglu MI, Cordonnier C, Al-Shahi Salman R, de Gans K, Koopman MM, Brand A, et al. Platelet transfusion versus standard care after acute stroke due to spontaneous cerebral haemorrhage associated with antiplatelet therapy (PATCH): a randomised, open-label, phase 3 trial. Lancet 2016;387:2605-13.

62. Choi PA, Parry PV, Bauer JS, Zusman BE, Panczykowski DM, Puccio AM, et al. Use of aspirin and P2Y12 response assays in detecting reversal of platelet inhibition with platelet transfusion in patients with traumatic brain injury on antiplatelet therapy. Neurosurgery 2017;80:98-104.

63. Naidech AM, Liebling SM, Rosenberg NF, Lindholm PF, Bernstein RA, Batjer $\mathrm{HH}$, et al. Early platelet transfusion improves platelet activity and may improve outcomes after intracerebral hemorrhage. Neurocrit Care 2012;16:82-7.

64. Furay E, Daley M, Teixeira PG, Coopwood TB, Aydelotte JD, Malesa N, et al. Goal-directed platelet transfusions correct platelet dysfunction and may improve survival in patients with severe traumatic brain injury. J Trauma Acute Care Surg 2018;85:881-7.

65. Tcheng JE. Clinical challenges of platelet glycoprotein IIb/IIIa receptor inhibitor therapy: bleeding, reversal, thrombocytopenia, and retreatment. Am Heart J 2000;139(2 Pt 2):S38-45.

66. Calmer S, Ferkau A, Larmann J, Johanning K, Czaja E, Hagl C, et al. Desmopressin (DDAVP) improves recruitment of activated platelets to collagen but simultaneously increases platelet endothelial interactions in vitro. Platelets 2014;25:8-15.

67. Mannucci PM, Remuzzi G, Pusineri F, Lombardi R, Valsecchi C, Mecca G, et al. Deamino-8-D-arginine vasopressin shortens the bleeding time in uremia. N Engl J Med 1983;308:8-12.

68. Reiter RA, Mayr F, Blazicek H, Galehr E, Jilma-Stohlawetz P, Domanovits $\mathrm{H}$, et al. Desmopressin antagonizes the in vitro platelet dysfunction induced by GPIIb/IIIa inhibitors and aspirin. Blood 2003;102:4594-9.

69. Wademan BH, Galvin SD. Desmopressin for reducing postoperative blood loss and transfusion requirements following cardiac surgery in adults. Interact Cardiovasc Thorac Surg 2014;18:36070.

70. Jin L, Ji HW. Effect of desmopressin on platelet aggregation and blood loss in patients undergoing valvular heart surgery. Chin Med J (Engl) 2015;128:644-7.

71. Naidech AM, Maas MB, Levasseur-Franklin KE, Liotta EM, Guth JC, Berman M, et al. Desmopressin improves platelet activity in acute intracerebral hemorrhage. Stroke 2014;45:2451-3.

72. Masotti L, Di Napoli M, Godoy DA, Rafanelli D, Liumbruno G, Koumpouros N, et al. The practical management of intracerebral hemorrhage associated with oral anticoagulant therapy. Int J Stroke 2011;6:228-40.

73. Pabinger I, Brenner B, Kalina U, Knaub S, Nagy A, Ostermann $\mathrm{H}$, et al. Prothrombin complex concentrate (Beriplex $\mathrm{P} / \mathrm{N}$ ) for emergency anticoagulation reversal: a prospective multinational clinical trial.J Thromb Haemost 2008;6:622-31.

74. Steiner T, Poli S, Griebe M, Hüsing J, Hajda J, Freiberger A, et al. Fresh frozen plasma versus prothrombin complex concentrate in patients with intracranial haemorrhage related to vitamin Kantagonists (INCH): a randomised trial. Lancet Neurol 2016;15:56673.

75. Dias JD, Norem K, Doorneweerd DD, Thurer RL, Popovsky MA, Omert LA. Use of thromboelastography (TEG) for detection of new oral anticoagulants. Arch Pathol Lab Med 2015;139:665-73.

76. Marlu R, Hodaj E, Paris A, Albaladejo P, Cracowski JL, Pernod G. Effect of non-specific reversal agents on anticoagulant activity of dabigatran and rivaroxaban: a randomised crossover ex vivo study in healthy volunteers. Thromb Haemost 2012;108:217-24.

77. Connolly SJ, Crowther M, Eikelboom JW, Gibson CM, Curnutte JT, Lawrence JH, et al. Full study report of andexanet alfa for bleeding associated with factor Xa inhibitors. N Engl J Med 2019;380:1326-35. 
78. Pollack CV Jr, Reilly PA, Weitz JI. Dabigatran reversal with idarucizumab. N Engl J Med 2017;377:1691-2.

79. Sarode R, Milling TJ Jr, Refaai MA, Mangione A, Schneider A, Durn BL, et al. Efficacy and safety of a 4-factor prothrombin complex concentrate in patients on vitamin $\mathrm{K}$ antagonists presenting with major bleeding: a randomized, plasma-controlled, phase IIIb study. Circulation 2013;128:1234-43.
80. Goldstein JN, Refaai MA, Milling TJ Jr, Lewis B, Goldberg-Alberts R, Hug BA, et al. Four-factor prothrombin complex concentrate versus plasma for rapid vitamin $\mathrm{K}$ antagonist reversal in patients needing urgent surgical or invasive interventions: a phase $3 \mathrm{~b}$, open-label, non-inferiority, randomised trial. Lancet 2015;385:2077-87. 